\title{
Freewheel Running Prevents Learned Helplessness/ Behavioral Depression: Role of Dorsal Raphe Serotonergic Neurons
}

\author{
Benjamin N. Greenwood, ${ }^{1,3}$ Teresa E. Foley, ${ }^{1}$ Heidi E. W. Day, ${ }^{2,3}$ Jay Campisi, ${ }^{1,3}$ Sayamwong H. Hammack, ${ }^{2,3}$ \\ Serge Campeau, ${ }^{2,3}$ Steven F. Maier, ${ }^{2,3}$ and Monika Fleshner ${ }^{1,3}$ \\ Departments of ${ }^{1}$ Kinesiology and Applied Physiology and ${ }^{2}$ Psychology, ${ }^{3}$ Center for Neuroscience, University of Colorado, Boulder, Colorado $80309-0354$
}

Serotonin (5-HT) neurons in the dorsal raphe nucleus (DRN) are implicated in mediating learned helplessness (LH) behaviors, such as poor escape responding and expression of exaggerated conditioned fear, induced by acute exposure to uncontrollable stress. DRN 5-HT neurons are hyperactive during uncontrollable stress, resulting in desensitization of 5-HT type 1A (5-HT1A) inhibitory autoreceptors in the DRN. 5-HT1A autoreceptor downregulation is thought to induce transient sensitization of DRN 5-HT neurons, resulting in excessive 5-HT activity in brain areas that control the expression of learned helplessness behaviors. Habitual physical activity has antidepressant/ anxiolytic properties and results in dramatic alterations in physiological stress responses, but the neurochemical mediators of these effects are unknown. The current study determined the effects of 6 weeks of voluntary freewheel running on LH behaviors, uncontrollable stress-induced activity of DRN 5-HT neurons, and basal expression of DRN 5-HT1A autoreceptor mRNA. Freewheel running prevented the shuttle box escape deficit and the exaggerated conditioned fear that is induced by uncontrollable tail shock in sedentary rats. Furthermore, double c-Fos/5-HT immunohistochemistry revealed that physical activity attenuated tail shock-induced activity of 5-HT neurons in the rostral-mid DRN. Six weeks of freewheel running also resulted in a basal increase in 5-HT1A inhibitory autoreceptor mRNA in the rostral-mid DRN. Results suggest that freewheel running prevents behavioral depression/LH and attenuates DRN 5-HT neural activity during uncontrollable stress. An increase in 5-HT1A inhibitory autoreceptor expression may contribute to the attenuation of DRN 5-HT activity and the prevention of LH in physically active rats.

Key words: exercise; depression; anxiety; c-Fos; 5-HT1A autoreceptor; stress

\section{Introduction}

An increase in stress resistance is one potential mechanism mediating the well accepted antidepressant and anxiolytic properties of physical activity (Babyak et al., 2000; Taylor, 2000; Salmon, 2001; Brosse et al., 2002). Indeed, stressful events often precipitate and exacerbate psychiatric disorders such as depression and anxiety (Chorpita and Barlow, 1998; Kendler et al., 1999), and, compared with sedentary rats, several weeks of previous, voluntary access to running wheels results in dramatic alterations in immunological (Dishman et al., 1995; Fleshner, 2000; Avula et al., 2001; Moraska and Fleshner, 2001; Fleshner et al., 2002), neurochemical (Dunn et al., 1996; Dishman et al., 1997b; Soares et al., 1999; Greenwood et al., 2003), and behavioral (Dishman et al., 1996, 1997a; Solberg et al., 1999; Moraska and Fleshner, 2001) responses to stress.

Behavioral depression or learned helplessness ( $\mathrm{LH})$ refers to the behavioral consequences of exposure to stressful events over which the organism has no control (Maier and Seligman, 1976; Weiss et al., 1981). For example, sedentary rats exposed to uncontrollable shocks, relative to controllable shocks, later exhibit a

\footnotetext{
Received 0ct. 28, 2002; revised Jan. 9, 2003; accepted Jan. 10, 2003.

Funding for these studies was provided by a grant awarded to M.F. from the National Institutes of Health (National Institute of Allergy and Infectious Disease, Al48555).

Correspondence should be addressed to Dr. Monika Fleshner, University of Colorado-Boulder, Campus Box 354, Boulder, C0 80309-0354. E-mail: Fleshner@colorado.edu.

Copyright $\odot 2003$ Society for Neuroscience $\quad 0270-6474 / 03 / 232889-10 \$ 15.00 / 0$
}

deficit in learning to escape from escapable stress (Seligman and Beagley, 1975; Weiss and Glazer, 1975) and exaggerated fear responding (Maier, 1990). LH behaviors expressed in laboratory animals resemble those of human depression and anxiety (Anisman and Zacharko, 1992; Yehuda and Antelman, 1993; Maier and Watkins, 1998) and are sensitive to antidepressant and anxiolytic drugs (Maier et al., 1990, 1994; Martin and Puech, 1996; Maudhuit et al., 1997). Although focusing only on shuttle box escape and excluding nonstressed controls, previous data suggest that freewheel running reduces LH (Dishman et al., 1997a).

Investigations into the neurochemical basis of LH have focused on 5-HT neurons of the dorsal raphe nucleus (DRN). This is reasonable given the role of 5-HT in depression and anxiety (Graeff et al., 1996; Kent et al., 1998; Anderson and Mortimore, 1999; Blier and de Montigny, 1999; Ninan, 1999; Blier, 2001b). Furthermore, the DRN is a primary source of 5-HT projections to regions implicated in affective and behavioral responses (Imai et al., 1986; Ma et al., 1991; Vertes, 1991; Kazakov et al., 1993). Attenuation of the activity of 5-HT neurons in the DRN during exposure to uncontrollable stress is sufficient to prevent LH. Indeed, exposure to uncontrollable stress, relative to controllable stress (which does not produce LH), results in hyperactivity of DRN 5-HT neurons (Maswood et al., 1998; Grahn et al., 1999), and LH behaviors can be both prevented and reversed by manipulations that decrease 5-HT neural activity in the DRN (Maier et al., 1994, 1995a). Therefore, physical activity might prevent LH 
by attenuating uncontrollable stress-induced activity of 5-HT neurons in the DRN.

5-HT1A inhibitory autoreceptors are involved in both behavioral stress responses and antidepressant action (Schreiber and De Vry, 1993; Blier, 2001a; Blier et al., 2001; Gingrich and Hen, 2001). 5-HT1A autoreceptors in the DRN are potent inhibitors of DRN 5-HT neural activity and 5-HT release both within the DRN and in DRN projections sites (Sprouse and Aghajanian, 1987; De Vry, 1995; Bosker et al., 1997; Casanovas et al., 1997, 2000). Hyperactivity of 5-HT neurons in the DRN during exposure to uncontrollable tail shock induces desensitization (Short et al., 2000) and downregulation (S. F. Maier, unpublished observation) of 5-HT1A autoreceptors, indicating a role for 5-HT1A autoreceptors in LH. 5-HT1A autoreceptor downregulation would remove a potentially important source of DRN 5-HT inhibition. Thus, when faced with a challenge after uncontrollable stress, the sensitized DRN would respond in an exaggerated manner, leading to a potentiated release of 5-HT in DRN projection sites (Petty et al., 1994; Amat et al., 1998a,b; Maswood et al., 1998), which is considered the proximal mediator of LH behaviors (Maier and Watkins, 1998).

The current study tests the effects of 6 weeks of voluntary freewheel running on $\mathrm{LH}$ behaviors and investigates the effect of freewheel running on uncontrollable stress-induced activation of 5-HT neurons in the DRN using double c-Fos/5-HT immunohistochemistry. Additionally, the effect of freewheel running on 5-HT1A autoreceptor mRNA expression in the DRN is determined using in situ hybridization. Results suggest that freewheel running prevents behavioral depression/LH and attenuates DRN 5-HT neural activity during uncontrollable stress. Freewheel running also produces a static upregulation of 5-HT1A inhibitory autoreceptors in the DRN, possibly contributing to the attenuation of DRN 5-HT neural activity, and the prevention of LH.

\section{Materials and Methods}

Animals. Adult, male Sprague Dawley rats (Harlan Sprague Dawley, Indianapolis, IN) weighing $214.13 \pm 40.7 \mathrm{gm}$ at time of arrival were used in all experiments. Rats were housed in a temperature- $\left(22^{\circ} \mathrm{C}\right)$ and humidity-controlled environment, were maintained on a $12 \mathrm{hr}$ light/ dark cycle (lights on 6 A.M.-6 P.M.), and had ad libitum access to food (LabChow) and water. Animals were acclimated to these housing conditions for 2 weeks before any experimental manipulation. Animals were housed individually in Nalgene Plexiglas cages $(45 \times 25.2 \times 14.7 \mathrm{~cm})$ with attached running wheels. Wheels were rendered immobile with metal stakes during the acclimation period for the physically active animals and during the duration of the experiments for the sedentary rats. Although individual housing can evoke some features of the stress response in rats (Sharp et al., 2002), single housing was necessary in these experiments to allow quantification of the activity of individual animals and to avoid competition for running wheels. Care was taken to minimize animal discomfort during all procedures. All experimental protocols were approved by the University of Colorado Animal Care and Use Committee. Rats were weighed weekly.

Activity. Animals were randomly assigned to either physically active or sedentary conditions. At the start of the activity phase, the wheels in the cages of physically active rats were unlocked, and these rats were allowed voluntary access to their wheels. Daily wheel revolutions were recorded digitally using Vital View software (Mini Mitter, Bend, OR), and distance was calculated by multiplying wheel circumference $(1.081 \mathrm{~m})$ by the number of revolutions. Voluntary freewheel running was used as the form of activity in these experiments because, unlike treadmill training, freewheel running does not result in physiological adaptations associated with chronic stress, such as thymic involution, adrenal hypertrophy, elevated basal corticosterone, decreased corticosterone binding globulin, or immunosuppression (Moraska et al., 2000), which suggests that freewheel running is not chronically stressful.
Uncontrollable stress protocol. Rats were randomly assigned either to be exposed to uncontrollable tail shock or to remain in their home cages (control). Stressed rats were given 100 tail shocks $(5 \mathrm{sec}, 1.5 \mathrm{~mA}$ ) on a 1 min variable-interval schedule while being restrained in Plexiglas tubes (23.4 $\mathrm{cm}$ long and $7.0 \mathrm{~cm}$ in diameter). After stressor termination, rats were returned to their home cages. Thus, physically active rats exposed to tail shock were allowed access to their running wheels after stressor exposure. All rats were stressed during their inactive (light) cycle, between 8 and 10 A.M. This tail shock protocol was used in these experiments because tail shock is a consistent, quantifiable stressor that is known to produce LH (Maier et al., 1995b), and we have used 100 tail shocks previously to document several stress-buffering effects of freewheel running (Fleshner, 2000; Moraska and Fleshner, 2001; Fleshner et al., 2002).

Behavioral testing. Both shuttle box escape learning and conditioned fear were tested $24 \mathrm{hr}$ after stress or control treatment, as described previously (Maier et al., 1993). Freezing was measured for the first $5 \mathrm{~min}$ after placement in the shuttle box $(46 \times 20.7 \times 20 \mathrm{~cm})$, during which time each rat ( $n=8$ per group) was scored every $8 \mathrm{sec}$ as either freezing or not freezing. To be scored as freezing, all four paws had to be on the shuttle box grid floor, and there had to be an absence of all movement except for that required for respiration. After this initial observation period, rats received two $0.6 \mathrm{~mA}$ foot shocks that could be terminated by crossing to the other side of the shuttle box [fixed ratio-1 (FR-1) trials]. Shocks terminated automatically after $30 \mathrm{sec}$ if escape had not occurred, and a 30 sec latency was assigned. Previous uncontrollable stress does not alter FR-1 shuttle box escape latencies (Maier et al., 1993); therefore, stressed and control animals were exposed to shocks of equal duration in this phase.

After the two FR-1 trials, rats were observed again for $20 \mathrm{~min}$ and scored for freezing as before. Previous work has indicated that this freezing is a measure of fear that has been conditioned to the contextual cue of the shuttle box (Fansclow and Lester, 1988). The post FR-1 observation period was followed by 3 more FR-1 escape trials and then by 25 FR-2 escape trials. FR-2 trials differed from FR-1 trials in that the rats were required to cross to the other side of the shuttle box and then back to terminate foot shock. Uncontrollable stress-induced escape deficits are typically revealed during the FR-2 trials. Shocks occurred with an average intertrial interval of $60 \mathrm{sec}$, and each shock was terminated after $30 \mathrm{sec}$ if an escape response had not occurred. A single test session lasted $\sim 50 \mathrm{~min}$ and was performed by an observer blind to treatment condition of the animals.

Immunohistochemistry. Physically active and sedentary rats $(n=8$ per group) were deeply anesthetized with sodium pentobarbital (Nembutal) $\sim 90$ min after tail shock termination, the latency at which c-Fos protein can be optimally detected in the DRN after 100 inescapable tail shocks (Grahn et al., 1999). Rats were perfused transcardially with $100 \mathrm{ml}$ of cold physiological saline, followed by $400-500 \mathrm{ml}$ of $4 \%$ paraformaldehyde in $0.1 \mathrm{M}$ phosphate buffer (PB). Extracted brains were postfixed in $4 \%$ paraformaldehyde for $1 \mathrm{hr}$ and then transferred to $\mathrm{PB}$, containing $0.1 \%$ sodium azide and $30 \%$ sucrose, and stored at $4^{\circ} \mathrm{C}$ until sectioning. After rapid freezing in isopentane and dry ice $\left(-40\right.$ to $\left.-50^{\circ} \mathrm{C}\right), 35 \mu \mathrm{m}$ coronal sections were cut on a cryostat (CM 1850, Leica Microsystems, Nussloch, Germany) at $-20^{\circ} \mathrm{C}$ and placed in $\mathrm{PB}$ containing $0.1 \%$ sodium azide. Sections were stored at $4^{\circ} \mathrm{C}$ until staining.

c-Fos/5-HT double labeling. Labeling for c-Fos and 5-HT occurred sequentially on floating, $35 \mu \mathrm{m}$ brain sections representing the rostral to caudal extent of the DRN according to the procedures outlined in Grahn et al. (1999). Tissue was first reacted for c-Fos immunoreactivity (IR). Briefly, sections were rinsed in $0.01 \mathrm{M}$ PBS followed by a $30 \mathrm{~min}$ incubation in $0.3 \%$ hydrogen peroxide. Sections were incubated at room temperature for $12 \mathrm{hr}$ in blocking solution containing $0.1 \%$ sodium azide, $0.5 \%$ Triton X-100, 5\% normal goat serum, and polyclonal rabbit antic-Fos IgG (Santa Cruz Antibodies, Santa Cruz, CA) at a dilution of $1: 15,000$. This incubation was followed by another series of washes in PBS after which the sections were incubated at room temperature for $2 \mathrm{hr}$ in blocking solution containing a 1:200 dilution of biotinylated goat anti-rabbit IgG (Jackson ImmunoResearch, West Grove, PA). Sections were then incubated with avidin-biotin-horseradish peroxidase complexes (ABC; Vectastain Elite ABC kit, Vector Laboratories, Burlingame, 
CA) in PBS containing 0.5\% Triton X-100 for $2 \mathrm{hr}$. After washes with PB, sections were placed in a solution containing $3,3^{\prime}$-diaminobenzidene (DAB), ammonium chloride, cobalt chloride, nickel ammonium sulfate, and glucose oxidase in PB for $10 \mathrm{~min}$. The peroxidase reaction was started by addition of glucose solution and reacted for 15-20 min, yielding a dark brown/black reaction product. The reaction was stopped by rinses in PBS.

Immediately after c-Fos staining, sections of the DRN were reacted for 5-HT IR. After PBS rinses, DRN sections were incubated in blocking solution for $30 \mathrm{~min}$. Tissue was then incubated in a 1:10,000 dilution of 5 -HT antibody (DiaSorin, Stillwater, MN) for $48 \mathrm{hr}$ at $4^{\circ} \mathrm{C}$. Sections were then placed in goat anti-rabbit IgG (1:200; Jackson ImmunoResearch) for $2 \mathrm{hr}$, followed by a $2 \mathrm{hr}$ incubation in PBS containing a 1:500 dilution of peroxidase anti-peroxidase (Sigma, St. Louis, MO). Tissue was rinsed in $\mathrm{PB}$ and reacted with $\mathrm{DAB}$ and glucose oxidase. The peroxidase reaction was initiated by addition of glucose and allowed to proceed for $\sim 15$ min, yielding a light brown reaction product. The reaction was stopped by PBS washes. All tissue was processed simultaneously so that direct comparisons between groups were possible.

Image analysis. An observer blind to the treatment condition of the subjects analyzed all brain sections. To determine whether physical activity status affected stress-induced activation of unique populations of 5-HT neurons within the DRN, the DRN was divided into dorsal, ventral, and lateral portions on the basis of the rat brain atlas by Paxinos and Watson (1998). Each of these regions was analyzed at independent rostral [-7.64 $\mathrm{mm}$ posterior to bregma (Paxinos and Watson, 1998)], mid $(-8.00 \mathrm{~mm}$ posterior to bregma), and caudal $(-8.30 \mathrm{~mm}$ posterior to bregma) levels, with the exception of the lateral wings, which are not present at the caudal level of analysis. Accordingly, six double-labeled sections of the DRN, one pair each corresponding to either the rostral, mid, or caudal DRN, were selected from each subject for analysis. Each section was assessed for the number of single c-Fos-positive nuclei, the number of single 5-HT-positive cells, and the number of double-labeled cells. Small, dark brown/black particles were counted as single c-Fosstained nuclei. Larger, light brown particles without a darker nucleus were counted as single 5-HT-stained cells. Larger, lighter brown particles that contained a darker nucleus were counted as double-labeled c-Fos/ 5-HT cells. Results are expressed as the mean number of single- or double-labeled cells. The values of each subject of single c-Fos, single 5-HT, and double-labeled cells at each rostrocaudal level of the DRN were obtained by averaging the two sections chosen for analysis at that level.

In situ hybridization for 5-HT1A autoreceptor mRNA in DRN. Between 8 and 11 A.M., sedentary rats $(n=8)$ and rats allowed voluntary access to running wheels for 6 weeks $(n=8)$ were killed by decapitation. Brains were removed and frozen rapidly in isopentane and dry ice $(-40$ to $-50^{\circ} \mathrm{C}$ ) and stored at $-80^{\circ} \mathrm{C}$ until sliced into $10 \mu \mathrm{m}$ coronal sections on a cryostat. DRN slices were thaw-mounted directly onto polylysinecoated slides and stored at $-80^{\circ} \mathrm{C}$ until processing for single-labeled radioactive in situ hybridization as described previously (Day and Akil, 1996). Briefly, sections were fixed in $4 \%$ paraformaldehyde for $1 \mathrm{hr}$, acetylated in $0.1 \mathrm{M}$ triethenolamine containing $0.25 \%$ acetic anhydride (10 min), and dehydrated in graded alcohol. A cRNA ribroprobe complementary to the 5-HT1A inhibitory autoreceptor was prepared from cDNA subclones in transcription vectors and labeled with $\left[{ }^{35} \mathrm{~S}\right] \mathrm{UTP}$ (Amersham Biosciences, Piscataway, NJ), using standard transcription methods. Riboprobes were diluted in $50 \%$ hybridization buffer containing $50 \%$ formamide, $10 \%$ dextran sulfate, $2 \times$ saline sodium citrate (SSC), 50 mm PBS, pH 7.4, $1 \times$ Denhardt's solution, and $0.1 \mathrm{mg} / \mathrm{ml}$ yeast tRNA. Brain sections representing the rostral to caudal extent of the DRN were hybridized with the probe overnight $\left(55^{\circ} \mathrm{C}\right)$. The next day, sections were washed in $2 \times \mathrm{SSC}$, treated with RNase A $(200 \mu \mathrm{g} / \mathrm{ml})$ for $1 \mathrm{hr}$ at $37^{\circ} \mathrm{C}$, and washed to a final stringency of $0.1 \times$ SSC at $65^{\circ} \mathrm{C}$ for $1 \mathrm{hr}$. Dehydrated, air-dried sections were exposed to X-ray film (Biomax-MR; Eastman Kodak, Rochester, NY) for 5 weeks. Slides (each containing four brain sections) from all rats were processed in a single in situ experiment to allow for direct comparisons.

Image analysis. Levels of 5-HT1A mRNA were analyzed by computerassisted optical densitometry. Brain section images were captured digitally (CCD camera, model XC-77; Sony, Tokyo, Japan), and the relative

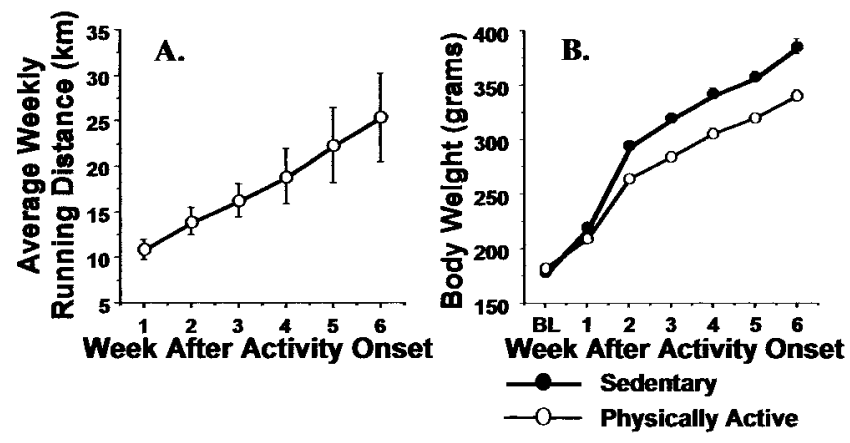

Figure 1. Adult male Sprague Dawley rats were allowed voluntary access to running wheels for 6 weeks or remained sedentary. $A$, The mean distance (kilometers) run each week by the physically active rats. $B$, The mean weekly body weight change (grams) of physically active and sedentary rats. Values represent group means \pm SEM. $B L$, Baseline.

optical density of the $\mathrm{x}$-ray film was determined using scion image version 4.0. A macro was written that enabled signal above background to be determined automatically. For each section, a background sample was taken over an area of white matter, and the signal threshold was calculated as mean gray value of background $+3.5 \mathrm{SD}$. The section was automatically density sliced at this value, so that only pixels with gray values above these criteria were included in the analysis. Results are expressed as mean integrated density, which reflects both the signal intensity and the number of pixels above assigned background (mean signal above background $\times$ number of pixels above background). Care was taken to ensure that equivalent areas were analyzed between animals. Quantification of 5-HT1A mRNA in the DRN occurred at both rostral-mid $[-7.64$ to $-8.0 \mathrm{~mm}$ posterior to bregma (Paxinos and Watson, 1998)] and caudal $(-8.3 \mathrm{~mm})$ levels. Four DRN sections were analyzed for each subject at each approximate rostrocaudal level. These four values at each level were then averaged to give a mean integrated density at each level for each subject.

Statistical analysis. Body weights were analyzed with repeated measures ANOVA. Escape latencies were collapsed into six blocks of five trials and analyzed with two-way (stress $\times$ activity), repeated measures ANOVA, followed by a Newman-Keuls analysis. Freezing scores were collapsed into 10 blocks ( 2 min each) and also analyzed with two-way (stress $X$ activity), repeated measures ANOVA followed by a NewmanKeuls analysis. Group differences in single c-Fos protein, single 5-HT, and double c-Fos/5-HT-labeled cells in each region of the DRN were analyzed by two-way (stress $\times$ activity) ANOVA. Group differences in DRN 5-HT1A mRNA were analyzed with one-way ANOVA. To determine the relationship between distance run and LH behaviors, c-Fos expression in the DRN, or expression of 5-HTla mRNA in the DRN, regression analysis was performed by simple regression on total distance run to escape latency, freezing score, double c-Fos/5-HT cells in the mid DRN, and 5-HT1A mRNA levels in the rostral-mid, dorsal DRN. Fisher protected least significant difference (F-PLSD) post hoc analysis was performed when required. $\alpha$ was set at 0.05 for each analysis. Actual group sizes varied within and between brain regions because of disruptions in tissue integrity incurred during brain removal, slicing, processing, etc.

\section{Results}

\section{Activity and body weight (Fig. 1)}

Weekly running distance and body weight change for Sprague Dawley rats used to investigate the effects of freewheel running on shuttle box escape and freezing behavior are shown in Figure 1. Running distance (Fig. $1 A$ ) and body weight (Fig. $1 B$ ) increased steadily over 6 weeks. Repeated measures ANOVA revealed significant main effects of time $\left(F_{(5,150)}=1003.87 ; p<0.0001\right)$ and activity $\left(F_{(1,150)}=46.17 ; p<0.0001\right)$ and a reliable time by activity interaction $\left(F_{(5,150)}=18.5 ; p<0.0001\right)$ on body weight. Physically active rats $(n=16)$ weighed less than sedentary rats $(n=16)$ by the end of the second week of freewheel access $(p<$ 
A.

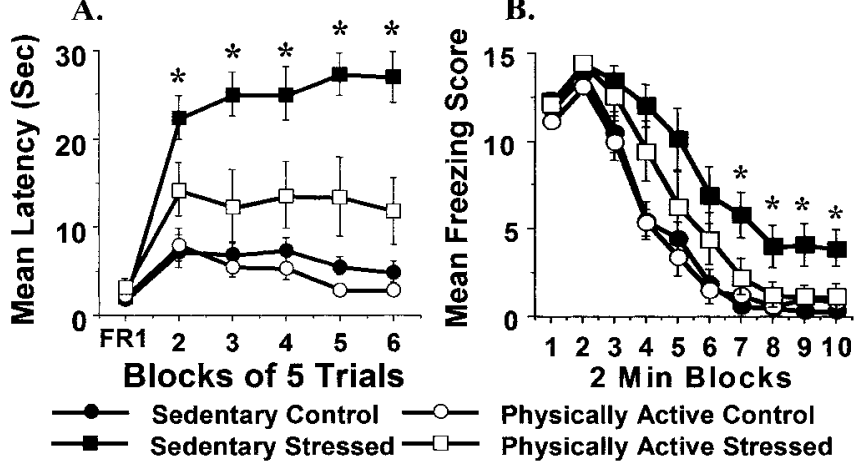

Figure 2. Sedentary and physically active rats were exposed to 100 inescapable tail shocks (Stressed) or remained in their home cages (Control). Shuttle box escape latencies and freezing behavior were measured sequentially $24 \mathrm{hr}$ later. $A$, Mean shuttle box escape latencies for one block of 5 FR- 1 trials (FR1) and five blocks of five FR-2 trials (2-6). B, The mean number of $8 \mathrm{sec}$ observation periods during which freezing occurred across blocks of 2 min after two shocks in the shuttle box. Values represent group means \pm SEM. Newman-Keuls analysis: ${ }^{*} p<0.05$ with respect to physically active stressed group.

0.0001 ) and remained lighter until the end of the study (sedentary mean at 6 weeks $=385.5 \pm 25.9$ gm; physically active mean at 6 weeks $=340.06 \pm 21.9 \mathrm{gm} ; p<0.0001)$. Both running distances and body weight changes for rats used in immunohistochemistry and in situ hybridization studies were similar to those reported in Figure 1 (data not shown).

\section{Shuttle box escape and freezing behavior (Fig. 2)}

To determine the effect of 6 weeks of voluntary freewheel running on LH behaviors, sedentary and physically active rats either were exposed to uncontrollable tail shock stress or remained in their home cages. Twenty-four hours later, rats were tested in shuttle boxes for escape performance and conditioned fear. Six weeks of voluntary freewheel running significantly reduced the effects of uncontrollable stress on shuttle box escape and freezing behavior. Escape latencies are shown in Figure $2 A$. Freewheel running did not, by itself, alter escape performance. No differences in escape latencies between groups during the FR-1 trial were found, however; ANOVA revealed reliable main effects of stress $\left(F_{(1,27)}=\right.$ $41.2 ; p<0.0001)$ and activity $\left(F_{(1,27)}=10.55 ; p=0.003\right)$, and a significant interaction between stress and activity conditions $\left(F_{(1,27)}=6.5 ; p=0.02\right)$ during FR-2 trials. A reliable interaction was found between FR-2 escape trials and stress treatment $\left(F_{(4,108)}=2.03 ; p=0.03\right)$ but not between escape trials and activity or escape trials, stress treatment, and activity. NewmanKeuls analysis revealed that sedentary rats exposed to uncontrollable stress displayed significantly longer FR-2 escape latencies compared with rats in all other groups during all five FR-2 trials. Only in the final two FR-2 trials did physically active rats exposed to uncontrollable stress differ from physically active controls. At no point during escape testing did the escape latencies of physically active controls and physically active stressed rats differ from those of sedentary animals not exposed to stress.

A similar pattern was present with regard to conditioned fear (Fig. 2 B). Six weeks of previous freewheel access significantly attenuated the effect of uncontrollable stress on freezing behavior. By itself, physical activity had no effect on fear conditioning. ANOVA revealed a reliable main effect of stress treatment $\left(F_{(1,27)}=18.48 ; p=0.0002\right)$ and a trend for activity $\left(F_{(1,27)}=\right.$ $3.49 ; p=0.07)$. The interaction between stress treatment and activity failed to reach statistical significance at $p=0.05\left(F_{(1,27)}=\right.$ 2.66; $p=0.1)$. There was a reliable interaction between $2 \mathrm{~min}$ blocks of freezing and stress treatment $\left(F_{(9,243)}=3.8 ; p=\right.$ 0.0002 ), but not between 2 min blocks of freezing and activity or 2 min blocks of freezing, stress treatment, and activity. NewmanKeuls post hoc comparisons are justified in this case because of the a priori hypothesis that sedentary rats exposed to uncontrollable stress would display exaggerated fear conditioning compared with physically active rats exposed to stress. Newman-Keuls analysis revealed that the groups did not differ in freezing during the first three 2 min blocks. Starting at block 4, however, sedentary stressed animals spent significantly more time freezing than both sedentary and physically active controls, and they remained different for the remainder of the testing session. Block 4 was the only time during which physically active stressed rats spent significantly more time freezing than sedentary controls. Starting at block 7, physically active stressed animals spent significantly less time freezing than sedentary stressed counterparts, and they remained different for the remainder of the session. At no point did the freezing behavior of physically active control rats differ from that of physically active stressed or sedentary control animals.

Simple regression analysis revealed no reliable correlations between the amount of running over 6 weeks and FR-2 escape latencies $(r=0.04 ; p=0.93)$ or the amount of running and average freezing time $(r=0.21 ; p=0.63)$.

\section{c-Fos expression in the DRN (Figs. 3, 4)}

Considerable evidence suggests that $\mathrm{LH}$ behaviors are dependent on hyperactivity of DRN 5-HT neurons during exposure to uncontrollable stress. Therefore, freewheel running could prevent LH by attenuating the activity of DRN 5-HT cells during uncontrollable stress. To test this hypothesis, stress-induced activity of 5-HT neurons of the DRN was compared between sedentary and physically active rats using double immunohistochemistry for the immediate early gene product, c-Fos, and 5-HT.

Photomicrographs $(12 \times$ magnification $)$ of the DRN taken from a sedentary rat exposed to uncontrollable tail shock are depicted in Figure 3. A-C represent coronal sections through the rostral $(-7.64 \mathrm{~mm}$ posterior from bregma), mid $(-8.00 \mathrm{~mm})$, and caudal $(-8.30 \mathrm{~mm})$ DRN chosen from each rat for analysis. Table 1 shows the mean number of single 5-HT-positive cells and single (5-HT negative) c-Fos-positive nuclei in each area of the DRN examined in sedentary and physically active rats. Neither stress nor activity treatment affected the number of 5-HTpositive cells anywhere in the DRN. Exposure to stress, however, did increase significantly the number of single c-Fos-positive particles in every region of the DRN examined, and freewheel running attenuated stress-induced c-Fos in non-5HT cells of the dorsal aspect of the rostral DRN. Freewheel running did not alter single c-Fos IR in any other DRN region.

The mean number of double c-Fos/5-HT-positive cells in the dorsal aspect of the DRN is shown in Figure $4 A$. The number of rats per group used in analysis of double-labeled cells in the DRN are the same as those reported in Table 1. Exposure to stress increased the number of double c-Fos/5-HT-positive cells throughout the rostrocaudal extent of the dorsal DRN, and freewheel running attenuated stress-induced c-Fos in serotonergic neurons of the rostral and mid dorsal DRN. ANOVA revealed reliable main effects of stress in the rostral $\left(F_{(1,21)}=82.96 ; p<\right.$ $0.0001)$, mid $\left(F_{(1,21)}=176.66 ; p<0.0001\right)$, and caudal $\left(F_{(1,21)}=\right.$ 63.8; $p<0.0001)$ aspects of the dorsal DRN. Additionally, ANOVA revealed reliable main effects of activity in the rostral $\left(F_{(1,21)}=11.61 ; p=0.003\right)$ and $\operatorname{mid}\left(F_{(1,21)}=15.04 ; p=0.0009\right)$, but not caudal, aspects of the dorsal DRN. Similarly, reliable interactions between stress and activity conditions were found in 


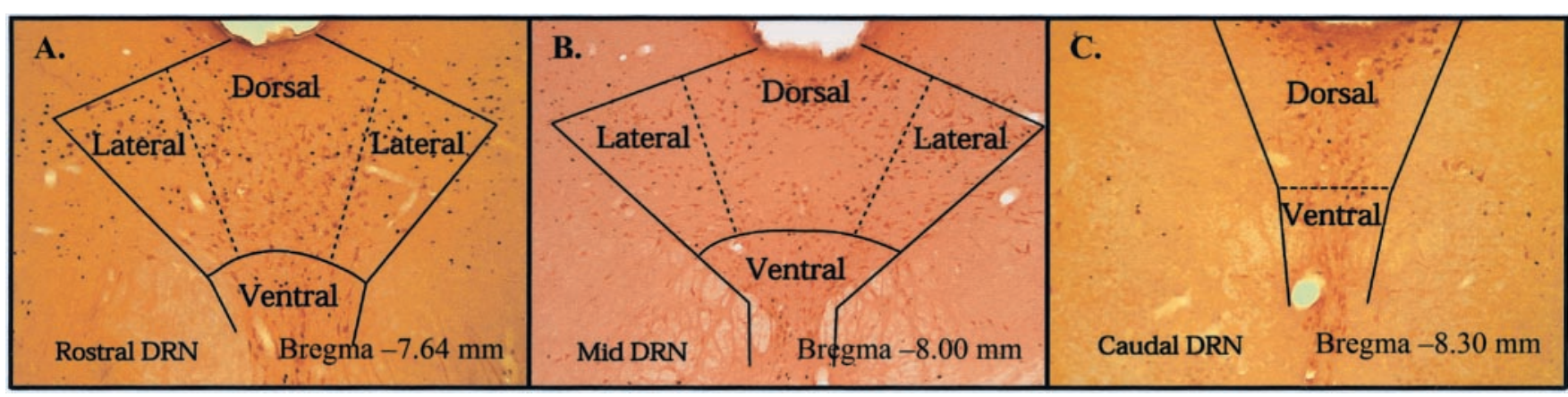

Figure 3. Photomicrographs ( $12 \times$ magnification) of coronal slices through the rostral $(A)$, mid $(B)$, and caudal $(C)$ dorsal raphe nucleus (DRN) of a sedentary rat exposed to inescapable tail shock stress and killed $90 \mathrm{~min}$ after stressor termination. Sections were double labeled for c-Fos (small black particles) and serotonin (Iarger, light brown particles). Delineated are the dorsal, ventral, and lateral aspects of the DRN in which quantification of single- and double-labeled cells occurred.

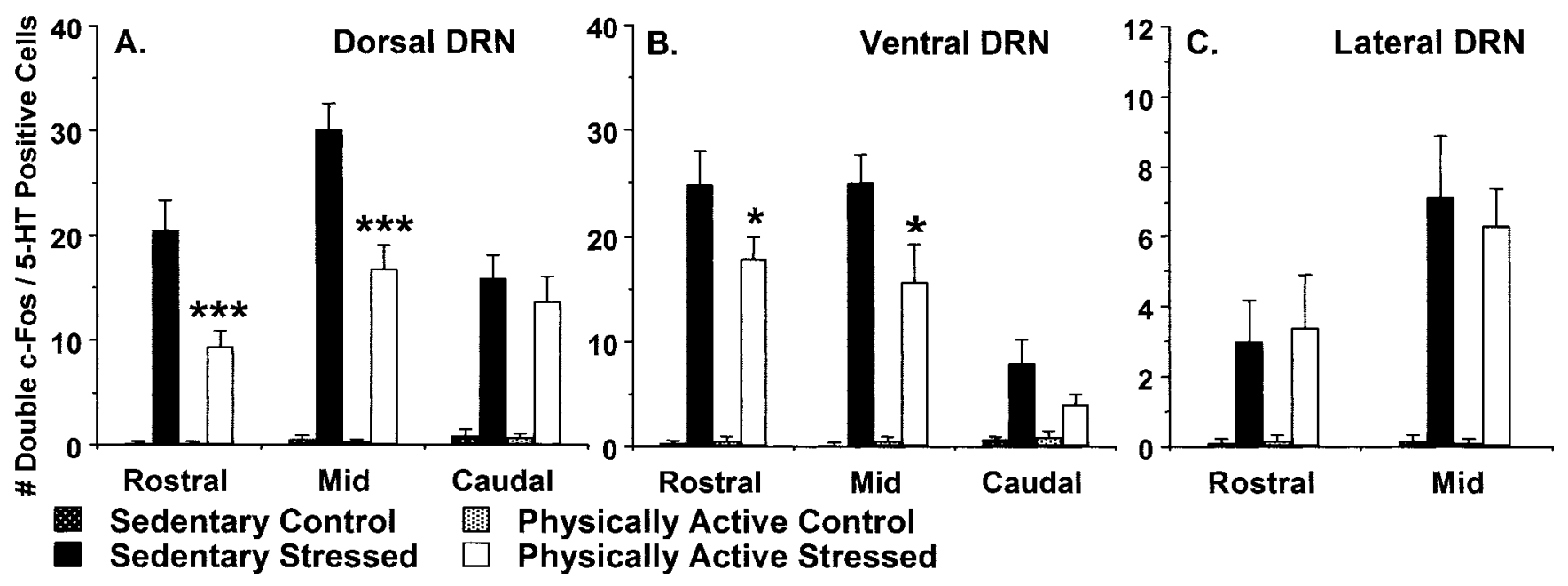

Figure 4. Activation of serotonergic (5-HT) neurons in the dorsal $(A)$, ventral $(B)$, and lateral $(C)$ aspects of the dorsal raphe nucleus (DRN) is represented by the number of double $\mathrm{C}-\mathrm{Fos} / 5-\mathrm{HT}-$ labeled cells. Sedentary and physically active rats were exposed to inescapable tail shock (Stressed) or remained in their home cages (Control). Ninety minutes after the final tail shock, brains were removed and processed for c-Fos and 5-HT immunoreactivity. Values represent mean number of double-labeled cells \pm SEM. F-PLSD: ${ }^{* *} p<0.0001,{ }^{*} p<0.05$ with respect to sedentary stressed group.

the rostral $\left(F_{(1,21)}=11.61 ; p=0.003\right)$ and $\operatorname{mid}\left(F_{(1,21)}=14.3\right.$; $p=0.001)$, but not caudal, dorsal DRN.

Figure $4 B$ shows the mean number of double c-Fos/5-HTpositive cells in the ventral aspect of the DRN. Like the dorsal aspect, tail shock exposure increased the number of doublelabeled cells throughout the rostrocaudal extent of the ventral DRN, and freewheel running reduced the effect of stress in the rostral and mid, but not caudal, ventral DRN. ANOVA revealed reliable main effects of stress in the rostral $\left(F_{(1,21)}=118.12 ; p<\right.$ $0.0001)$, $\operatorname{mid}\left(F_{(1,21)}=72.79 ; p<0.0001\right)$, and caudal $\left(F_{(1,21)}=\right.$ $18.59 ; p=0.0003)$ aspects of the ventral DRN. Although no main effects of activity were found, a trend for an interaction between stress and activity was found in the rostral ventral DRN $\left(F_{(1,21)}=\right.$ $3.44 ; p=0.07)$, whereas a reliable interaction was revealed in the mid ventral DRN $\left(F_{(1,21)}=4.2 ; p=0.05\right)$. Freewheel running did not alter the number of double-positive cells in the caudal ventral DRN.

The mean values of double c-Fos/5-HT-positive cells in the lateral aspect of the rostral and mid DRN are depicted in Figure $4 C$. Levels of c-Fos in the caudal aspect of the lateral DRN are not given because no appreciable lateral wings are present in the DRN at the caudal level of analysis. As in other DRN regions, exposure to stress elevated the number of double-positive cells in the rostral and mid aspects of the lateral DRN. Physical activity status did not affect the number of c-Fos/5-HT-positive neurons in the lateral DRN. ANOVA revealed reliable main effects of stress in the rostral $\left(F_{(1,21)}=9.25 ; p=0.006\right)$ and $\operatorname{mid}\left(F_{(1,20)}=44.82\right.$; $p<0.0001)$ aspects of the lateral DRN. No reliable main effects of activity or stress by activity interactions were found in the lateral DRN.

No significant correlation was found between running distance over 6 weeks and the number of double c-Fos/5-HT-labeled cells in the mid DRN $(r=0.07 ; p=0.88)$.

\section{5-HT1A autoreceptor mRNA in the DRN (Figs. 5, 6)}

One possible mechanism whereby freewheel running could attenuate the activity of DRN 5-HT neurons during uncontrollable stress, and consequentially prevent $\mathrm{LH}$, is by stimulating an upregulation of 5-HT1A inhibitory autoreceptors in the DRN. To investigate this possible mechanism, the level of 5-HT1A mRNA was quantified in the DRN of sedentary and physically active rats, in the absence of stress, using in situ hybridization. Because changes in stress-induced c-Fos expression in the DRN attributable to physical activity status were specific to the rostral-mid DRN (Fig. 4), 5-HT1A autoreceptor mRNA was quantified in the rostral-mid DRN and the caudal DRN. Figure $5 A-D$ depicts 5-HT1A autoreceptor mRNA in the rostral to caudal levels of the DRN. 
Table 1. Mean and SE of 5-HT-positive cells and single c-Fos-positive nuclei in different regions of the DRN of sedentary and physically active rats exposed to either uncontrollable tail shock (stressed) or control treatment

\begin{tabular}{|c|c|c|c|c|c|c|c|c|}
\hline \multirow[b]{2}{*}{ Dorsal raphe nucleus region } & \multicolumn{2}{|c|}{$\begin{array}{l}\text { Sedentary control } \\
(n=6)\end{array}$} & \multicolumn{2}{|c|}{$\begin{array}{l}\text { Sedentary stressed } \\
(n=6)\end{array}$} & \multicolumn{2}{|c|}{$\begin{array}{l}\text { Physically active control } \\
(n=6)\end{array}$} & \multicolumn{2}{|c|}{$\begin{array}{l}\text { Physically active stressed } \\
(n=7)\end{array}$} \\
\hline & Mean & SE & Mean & SE & Mean & SE & Mean & SE \\
\hline \multicolumn{9}{|l|}{ 5-HT-positive cells } \\
\hline \multicolumn{9}{|l|}{ Dorsal DRN } \\
\hline Rostral & 76.0 & 4.03 & 75.83 & 8.66 & 73.17 & 6.66 & 72.43 & 8.69 \\
\hline Mid & 105.67 & 10.53 & 98.66 & 7.68 & 98.17 & 10.09 & 101.14 & 8.88 \\
\hline Caudal & 72.83 & 4.0 & 75.83 & 7.98 & 64.33 & 4.06 & 79.0 & 5.2 \\
\hline \multicolumn{9}{|l|}{ Ventral DRN } \\
\hline Rostral & 62.83 & 3.27 & 64.83 & 3.86 & 68.33 & 3.58 & 70.43 & 6.24 \\
\hline Mid & 73.17 & 5.72 & 79.33 & 1.75 & 81.5 & 4.82 & 72.28 & 4.99 \\
\hline Caudal & 51.5 & 2.5 & 52.17 & 3.27 & 51.0 & 1.67 & 45.0 & 3.16 \\
\hline \multicolumn{9}{|l|}{ Lateral DRN } \\
\hline Rostral & 7.67 & 1.99 & 9.17 & 2.27 & 8.67 & 1.31 & 9.86 & 1.68 \\
\hline Mid & 63.33 & 3.24 & 44.83 & 3.72 & 53.17 & 4.16 & 51.67 & 5.21 \\
\hline \multicolumn{9}{|l|}{ Single c-Fos-positive nuclei } \\
\hline \multicolumn{9}{|l|}{ Dorsal DRN } \\
\hline Rostral $^{\ddagger \diamond \S}$ & 0.33 & 0.21 & $49.83^{* *}$ & 6.07 & 0.50 & 0.34 & $31.0^{* * \dagger}$ & 3.82 \\
\hline $\operatorname{Mid}^{\ddagger}$ & 0.17 & 0.17 & $24.33^{* *}$ & 4.24 & 0.33 & 0.21 & $24.43^{* *}$ & 2.75 \\
\hline Caudal $^{\ddagger}$ & 0.67 & 0.33 & $6.83^{* *}$ & 0.79 & 0.50 & 0.34 & $7.43^{* *}$ & 1.23 \\
\hline \multicolumn{9}{|l|}{ Ventral DRN } \\
\hline Rostral $^{\ddagger}$ & 0.33 & 0.21 & $12.83^{* *}$ & 1.54 & 0.50 & 0.22 & $8.86^{* *}$ & 2.94 \\
\hline $\mathrm{Mid}^{\ddagger}$ & 0.50 & 0.22 & $9.67^{* *}$ & 3.31 & 0.17 & 0.17 & $9.0^{* *}$ & 1.40 \\
\hline Caudal $^{\ddagger}$ & 0.33 & 0.42 & $4.0^{* *}$ & 0.82 & 0.67 & 0.49 & $3.86^{* *}$ & 0.91 \\
\hline \multicolumn{9}{|l|}{ Lateral DRN } \\
\hline Rostral $^{\ddagger}$ & 0.0 & 0.0 & $46.67^{* *}$ & 7.75 & 0.17 & 0.17 & $43.71^{* *}$ & 6.42 \\
\hline $\operatorname{Mid}^{\ddagger}$ & 0.17 & 0.17 & $43.16^{* *}$ & 4.55 & 0.0 & 0.0 & $46.5^{* *}$ & 5.18 \\
\hline
\end{tabular}

Two-way ANOVA: ${ }^{\ddagger}$ main effect of stress, $p<0.001 ;{ }^{\diamond}$ main effect of activity, $p<0.05 ;{ }^{\S}$ stress by activity interaction, $p<0.05$. Fisher protected least significant difference: ${ }^{* *} p<0.001$ versus control; ${ }^{\dagger} p<0.05$ versus sedentary stressed.

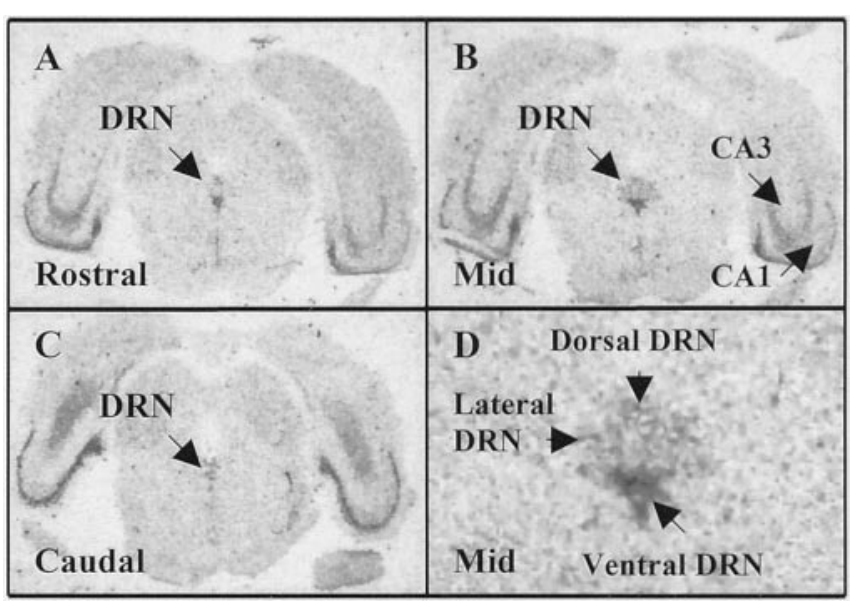

Figure 5. Representative autoradiographic coronal sections through the rostral $(A)$ mid $(B)$, and caudal $(C)$ dorsal raphe nucleus (DRN) of a sedentary rat processed for 5-HT1A autoreceptor mRNA in situ hybridization. 5-HT1A receptor mRNA can be seen in both the DRN and the hippocampus (CA1 and CA3). Labeled in D are the dorsal, ventral, and lateral subnuclei of the DRN ( $5 \times$ magnification) in which quantification of 5-HT1A autoreceptor mRNA occurred.

Figure $6 A$ shows that 5-HT1A receptor mRNA was increased in the dorsal aspect of the rostral-mid DRN after 6 weeks of freewheel access (ANOVA; $F_{(1,14)}=4.7 ; p=0.04$ ). Freewheel running, however, had no effect on the level of 5-HT1A mRNA in the caudal dorsal DRN (Fig. 6A), the ventral DRN (Fig. 6B), or the lateral DRN (Fig. 6C). Simple regression analysis revealed a slight, but nonsignificant, correlation between total distance run by physically active rats over the 6 week study and the level of 5-HT1A autoreceptor mRNA in the rostral-mid, dorsal DRN $(r=0.51 ; p=0.20)$.

\section{Discussion}

Six weeks of voluntary freewheel running reduced the behavioral effects of uncontrollable stress, supporting the hypothesis that freewheel running prevents LH. The attenuation of stressinduced activation of 5-HT neurons in the DRN during exposure to uncontrollable stress observed in physically active rats may be one mechanism whereby freewheel running prevents LH. Furthermore, the upregulation of 5-HT1A inhibitory autoreceptor mRNA found in the dorsal DRN after 6 weeks of freewheel access could potentially contribute to the reduction in DRN 5-HT activity and the prevention of LH.

Physical activity status had a significant impact on LH behaviors. Consistent with previous reports (Maier et al., 1993), exposure to uncontrollable tail shock led to poor escape performance and exaggerated fear conditioning in sedentary rats. Six weeks of voluntary access to running wheels before stressor exposure, however, caused a significant reduction in LH behaviors compared with sedentary, stressed counterparts. These observations support and extend previous work by Dishman et al. (1997a), who reported that 9-12 weeks of freewheel running, compared with sedentary housing, reduced the time to escape from escapable foot shock after exposure to uncontrollable stress, and support the antidepressant/anxiolytic properties of physical activity. Importantly, the beneficial responses to behavioral testing observed in physically active rats after exposure to stress are not likely caused by a general strength benefit of freewheel running, because physically active rats not exposed to tail shock did not escape any faster, or freeze any less, than sedentary control rats.

Six weeks of freewheel access attenuated uncontrollable stressinduced c-Fos expression in 5-HT-immunoreactive neurons of the DRN. This attenuation was not caused by a reduction in the number of 5-HT neurons in the DRN of physically active rats, nor was it caused by a globally suppressive effect of physical activity 


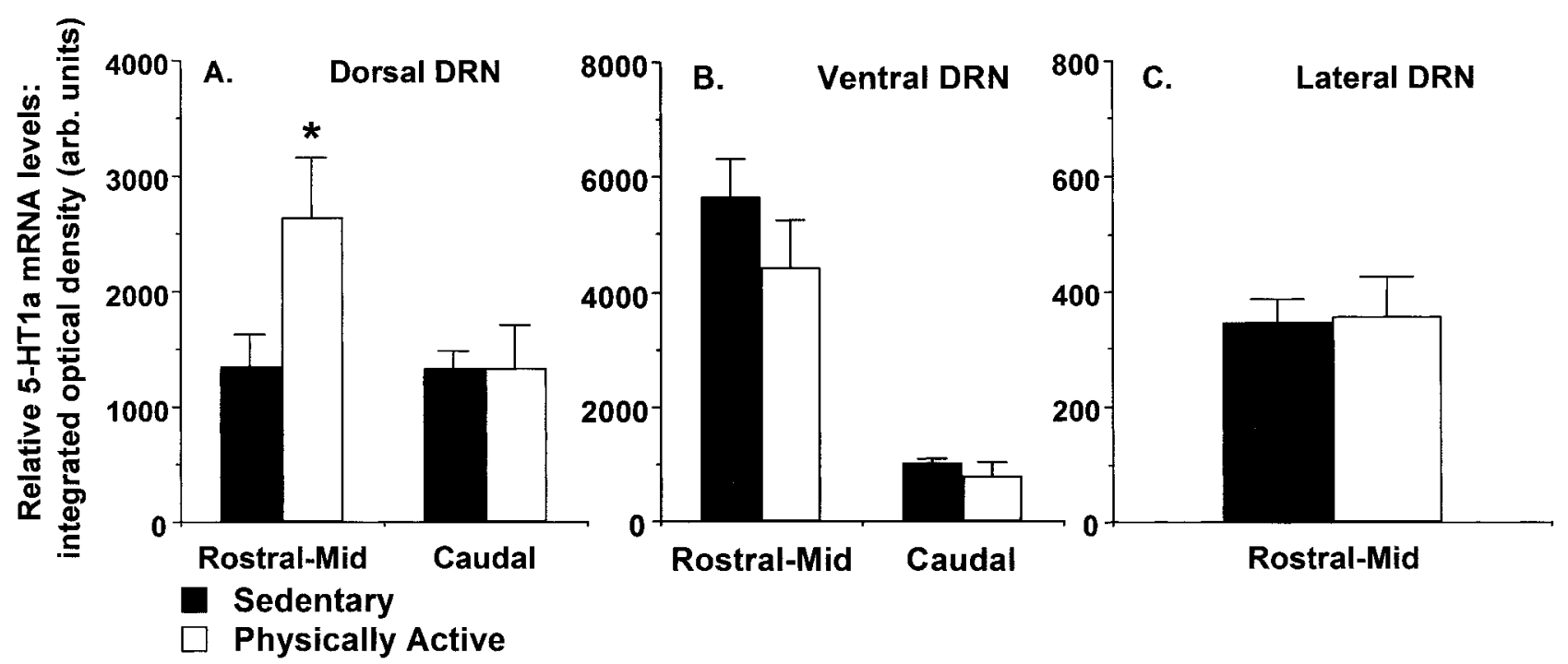

Figure 6. Expression of 5-HT1A autoreceptor mRNA in the dorsal $(A)$, ventral $(B)$, and lateral $(C)$ dorsal raphe nucleus $(D R N)$ of sedentary rats and rats allowed 6 weeks of voluntary access to running wheels (Physically Active). Values represent the mean integrated density \pm SEM. ANOVA: ${ }^{*} p<0.05$ with respect to sedentary group.

on c-Fos induction, because the c-Fos response to stress in non5-HT neurons of the DRN, with the exception of the dorsal rostral DRN, was not altered by freewheel running. A reduction in c-Fos expression in DRN 5-HT neurons is indicative of decreased stress-induced 5-HT neural activity in the DRN of physically active rats, a consequence of which may be attenuation of 5-HT release both within the DRN and in DRN projection sites during stress. Because 5-HT release is dependent on the type of stressor and the brain region in which it is measured (Kirby et al., 1995, 1997), the effect of freewheel running on attenuating 5-HT release may be stressor and brain region specific. However, Dishman et al. (1997a) reported that 9-12 weeks of freewheel running attenuated uncontrollable foot shock-induced elevations in the 5-HT metabolite, 5-hydroxyindole acetic acid, in two DRN projections sites, the hippocampus and amygdala, which is consistent with decreased 5-HT activity in these regions. Although the DRN is not the sole source of 5-HT to the hippocampus and amygdala (Imai et al., 1986), these observations reflect decreased stress-induced 5-HT neural activity in the DRN of physically active rats.

Attenuation of DRN 5-HT neural activity during uncontrollable stress may contribute to the protective effect of freewheel running against the behavioral effects of uncontrollable stress. Indeed, previous work has indicated that reducing 5-HT neural activity in the DRN is sufficient to prevent LH (Maier et al., 1994, 1995a), and, relative to uncontrollable tail shock, behavioral control over tail shock exposure prevents LH and similarly reduces c-Fos expression in DRN 5-HT neurons (Grahn et al., 1999). Although these results are consistent with the idea that freewheel running prevents LH by reducing 5 -HT neural activity in the DRN during uncontrollable stress, future studies are needed to determine the necessity of this attenuation in the protective effect of freewheel running against $\mathrm{LH}$.

5-HT1A inhibitory autoreceptor mRNA was increased in the dorsal aspect of the rostral-mid DRN after 6 weeks of freewheel running. Although 5-HT1A mRNA is only an indirect indication of 5-HT1A autoreceptor expression, data suggest that freewheel running increases gene expression of the 5-HT1A inhibitory autoreceptor in the DRN. This result is in contrast to data reported by Dey (1994), which indicated that 4 weeks of swimming in- duced a subsensitivity of the 5-HT1A autoreceptor as assessed by the hyperphagic response elicited by intraperitoneal administration of the selective 5-HT1A agonist $(+)-8$-hydroxy-2-(di- $N$ propylamino) tetralin. This apparent discrepancy may be explained by the fact that Dey (1994) used chronic forced swimming as the mode of physical activity. In contrast to voluntary freewheel running, many of the physiological changes associated with forced exercise mirror those produced by exposure to chronic stress (Moraska et al., 2000). Indeed, subsensitivity of 5-HT1A autoreceptors has been reported after exposure to a novel environment (Laaris et al., 1997) and chronic mild stress (Lanfumey et al., 1999). Therefore, previous observations on the effects of forced exercise on 5-HT systems may be confounded by unforeseen adaptations to chronic stress and thus may not represent effects of physical activity per se.

Interestingly, differences in stress-induced DRN c-Fos expression attributable to physical activity status were evident in the rostral-mid DRN and were more robust in the dorsal aspect, paralleling the regionally specific differences in DRN 5-HT1A inhibitory autoreceptor mRNA between sedentary and physically active rats. This anatomical similarity suggests a causal link between increased 5-HT1A autoreceptors and attenuation of 5-HT neural activity in the DRN of physically active rats. DRN 5-HT1A inhibitory autoreceptor upregulation could contribute to the attenuation of DRN 5-HT neural activity by enhancing autoinhibition of DRN 5-HT cell firing. Furthermore, the increase in 5-HT1A autoreceptors in the DRN of physically active rats could contribute directly to the prevention of LH by conveying resistance to stress-induced downregulation of DRN 5-HT1A inhibitory autoreceptors caused by an increased density of 5-HT1A autoreceptors before stress.

Although the current study focused on DRN 5-HT1A autoreceptors, 5-HT1B autoreceptors also regulate DRN 5-HT neural activity and 5-HT release (Adell et al., 2001) and are altered by stress (Edwards et al., 1991; Neumaier et al., 1997). Rats genetically bred for resistance to LH have a higher density of 5-HT1B autoreceptor mRNA in the DRN compared with LH-susceptible rats (Neumaier et al., 2002), suggesting a role for the 5-HT1B autoreceptor in resistance to $\mathrm{LH}$. Further research is required to determine whether adaptations in the 5 -HT1B autoreceptor are 
also involved in the attenuation of uncontrollable stress-induced DRN 5-HT neural activity and the prevention of LH observed in physically active rats.

The observation that the DRN is sensitive to the physical activity status of the organism is not surprising. 5-HT is clearly implicated in the modulation of motor activity (Jacobs and Fornal, 1997). The rostral-mid DRN projects to regions involved in motor control, such as the caudate putamen and substantia nigra (Imai et al., 1986; Lowry, 2002). Increases in central 5-HT during exercise coincide with the onset of fatigue (Blomstrand et al., 1988, 1989; Davis and Bailey, 1997), and administration of a 5-HT2 receptor antagonist increases running time to exhaustion (Bailey et al., 1993), suggesting that decreasing 5-HT responses during exercise may delay fatigue. Previous freewheel running delays the onset of fatigue as assessed by a longer treadmill running time to exhaustion (Campisi et al., 2003). Therefore, the upregulation of DRN 5-HT1A inhibitory autoreceptors produced by freewheel running could delay fatigue by restraining the release of 5-HT to DRN projection sites important in regulating fatigue during exercise (Davis and Bailey, 1997; Gomez-Merino et al., 2001).

In addition to motor regions, the rostral-mid DRN also projects to brain areas involved in affective and behavioral stress responses, such as the cortex, hippocampus, amygdala, and hypothalamus (Imai et al., 1986; Ma et al., 1991; Vertes, 1991; Kazakov et al., 1993; Lowry, 2002). Interestingly, divergent axonal projections from neurons in the DRN to both motor regions and behavior-modulatory regions, such as the amygdala, have been reported (Imai et al., 1986). It seems reasonable to suggest the possibility, therefore, that the attenuation of stress-induced 5-HT neural activity observed in the rostral-mid DRN of physically active rats is a consequence of an adaptation in central motor and fatigue circuits (including the DRN) brought about by habitual freewheel running.

Rats allowed voluntary access to running wheels increased running distance steadily over 6 weeks and gained less body weight than their sedentary counterparts, responses typical of Sprague Dawley rats (Moraska and Fleshner, 2001; Fleshner et al., 2002). The fact that no significant relationships between total distance run by physically active rats over 6 weeks and reduced escape and freezing time, reduced number of double c-Fos/5-HT-labeled cells, and increased 5-HT1A autoreceptor mRNA were found suggests that meeting a minimum threshold, $\leq 6$ weeks, of freewheel access is required to convey the behavioral and neurochemical responses observed in the current study.

In conclusion, freewheel running reduced the behavioral effects of exposure to uncontrollable stress. An attenuation of 5-HT neural activity in the DRN, perhaps induced by an upregulation of 5-HT1A inhibitory autoreceptors, may contribute to the prevention of LH observed in physically active rats. These results further support a role for the DRN in mediating the behavioral effects of uncontrollable stress and suggest that the DRN may be an important structure involved in the antidepressant and anxiolytic properties of physical activity.

\section{References}

Adell A, Celada P, Artigas F (2001) The role of 5-HT1B receptors in the regulation of serotonin cell firing and release in the rat brain. J Neurochem 79:172-182.

Amat J, Matus-Amat P, Watkins LR, Maier SF (1998a) Escapable and inescapable stress differentially and selectively alter extracellular levels of 5-HT in the ventral hippocampus and dorsal periaqueductal gray of the rat. Brain Res 797:12-22.
Amat J, Matus-Amat P, Watkins LR, Maier SF (1998b) Escapable and inescapable stress differentially alter extracellular levels of 5-HT in the basolateral amygdala of the rat. Brain Res 812:113-120.

Anderson IM, Mortimore C (1999) 5-HT and human anxiety. Evidence from studies using acute tryptophan depletion. Adv Exp Med Biol 467:43-55.

Anisman H, Zacharko RM (1992) Depression as a consequence of inadequate neurochemical adaptation in response to stressors. Br J Psychiatry [Suppl]15:36-43.

Avula CP, Muthukumar AR, Zaman K, McCarter R, Fernandes G (2001) Inhibitory effects of voluntary wheel exercise on apoptosis in splenic lymphocyte subsets of C57BL/6 mice. J Appl Physiol 91:2546-2552.

Babyak M, Blumenthal JA, Herman S, Khatri P, Doraiswamy M, Moore K, Craighead WE, Baldewicz TT, Krishnan KR (2000) Exercise treatment for major depression: maintenance of therapeutic benefit at 10 months. Psychosom Med 62:633-638.

Bailey SP, Davis JM, Ahlborn EN (1993) Serotonergic agonists and antagonists affect endurance performance in the rat. Int J Sports Med 14:330333.

Blier P (2001a) Pharmacology of rapid-onset antidepressant treatment strategies. J Clin Psychiatry 62:12-17.

Blier P (2001b) Crosstalk between the norepinephrine and serotonin systems and its role in the antidepressant response. J Psychiatry Neurosci 26:S3-10.

Blier P, de Montigny C (1999) Serotonin and drug-induced therapeutic responses in major depression, obsessive-compulsive and panic disorders. Neuropsychopharmacology 21:91S-98S.

Blier P, Haddjeri N, Szabo ST, Dong J (2001) Enhancement of serotoninergic function: a sometimes insufficient cause of antidepressant action. Hum Psychopharmacol 16:23-27.

Blomstrand E, Celsing F, Newsholme EA (1988) Changes in plasma concentrations of aromatic and branched-chain amino acids during sustained exercise in man and their possible role in fatigue. Acta Physiol Scand 133:115-121.

Blomstrand E, Perrett D, Parry-Billings M, Newsholme EA (1989) Effect of sustained exercise on plasma amino acid concentrations and on 5-hydroxytryptamine metabolism in six different brain regions in the rat. Acta Physiol Scand 136:473-481.

Bosker F, Vrinten D, Klompmakers A, Westenberg H (1997) The effects of a 5-HT1A receptor agonist and antagonist on the 5-hydroxytryptamine release in the central nucleus of the amygdala: a microdialysis study with flesinoxan and WAY 100635. Naunyn Schmiedebergs Arch Pharmacol 355:347-353.

Brosse AL, Sheets ES, Lett HS, Blumenthal JA (2002) Exercise and the treatment of clinical depression in adults: recent findings and future directions. Sports Med 32:741-760.

Campisi J, Leem TH, Greenwood BN, Hansen MK, Moraska A, Fleshner M (2003) Habitual physical activity facilitates stress-induced intracellular HSP72 induction in brain, peripheral and immune tissues. Am J Physiol Regul Integr Comp Physiol 284:R520-R530.

Casanovas JM, Lesourd M, Artigas F (1997) The effect of the selective 5-HT1A agonists alnespirone (S-20499) and 8-OH-DPAT on extracellular 5-hydroxytryptamine in different regions of rat brain. $\mathrm{Br} \mathrm{J}$ Pharmacol 122:733-741.

Casanovas JM, Berton O, Celada P, Artigas F (2000) In vivo actions of the selective 5-HT1A receptor agonist BAY x 3702 on serotonergic cell firing and release. Naunyn Schmiedebergs Arch Pharmacol 362:248-254.

Chorpita BF, Barlow DH (1998) The development of anxiety: the role of control in the early environment. Psychol Bull 124:3-21.

Davis JM, Bailey SP (1997) Possible mechanisms of central nervous system fatigue during exercise. Med Sci Sports Exer 29:45-57.

Day HE, Akil H (1996) Differential pattern of c-fos mRNA in rat brain following central and systemic administration of interleukin-1-beta: implications for mechanism of action. Neuroendocrinology 63:207-218.

De Vry J (1995) 5-HT1A receptor agonists: recent developments and controversial issues. Psychopharmacology (Berl) 121:1-26.

Dey S (1994) Physical exercise as a novel antidepressant agent: possible role of serotonin receptor subtypes. Physiol Behav 55:323-329.

Dishman RK, Warren JM, Youngstedt SD, Yoo H, Bunnell BN, Mougey EH, Meyerhoff JL, Friedmann LJ, Evans DL (1995) Activity-wheel running attenuates suppression of natural killer cell activity after footshock. J Appl Physiol 78:1547-1554. 
Dishman RK, Dunn AL, Youngstedt SD, Davis JM, Burgess ML, Wilson SP, Wilson MA (1996) Increased open field locomotion and decreased striatal GABAA binding after activity wheel running. Physiol Behav 60:699-705.

Dishman RK, Renner KJ, Youngstedt SD, Reigle TG, Bunnell BN, Burke KA, Yoo HS, Mougey EH, Meyerhoff JL (1997a) Activity wheel running reduces escape latency and alters brain monoamine levels after footshock. Brain Res Bull 42:399-406.

Dishman RK, Warren JM, Youngstedt SD, Yoo H, Bunnell BN, Mougey EH, Meyerhoff JL, Friedmann LJ, Evans DL (1997b) Brain monoamines, exercise, and behavioral stress: animal models. Med Sci Sports Exer 29:63-74.

Dunn AL, Reigle TG, Youngstedt SD, Armstrong RB, Dishman RK (1996) Brain monoamines and metabolites after treadmill training and wheel running in rats. Med Sci Sports Exer 28:204-209.

Edwards E, Harkins K, Wright G, Henn FA (1991) 5-HT1b receptors in an animal model of depression. Neuropharmacology 30:101-105.

Fanselow M, Lester L (1988) A functional behavioristic approach to aversively motivated behavior: predatory imminence as a determinant of the topography of defensive behavior. In: Evolution and learning (Bolles RC, Beecher MD, eds), pp 185-211. Hillsdale, NJ: Erlbaum.

Fleshner M (2000) Exercise and neuroendocrine regulation of antibody production: protective effect of physical activity on stress-induced suppression of the specific antibody response. Int J Sports Med 21:S14-S19.

Fleshner M, Campisi J, Deak T, Greenwood BN, Kintzel JA, Leem TH, Smith TP, Sorensen B (2002) Acute stressor exposure facilitates innate immunity more in physically active than in sedentary rats. Am J Physiol Regul Integr Comp Physiol 282:R1680-1686.

Gingrich JA, Hen R (2001) Dissecting the role of the serotonin system in neuropsychiatric disorders using knockout mice. Psychopharmacology (Berl) 155:1-10

Gomez-Merino D, Bequet F, Berthelot M, Chennaoui M, Guezennec CY (2001) Site-dependent effects of an acute intensive exercise on extracellular 5-HT and 5-HIAA levels in rat brain. Neurosci Lett 301:143-146.

Graeff FG, Guimaraes FS, De Andrade TG, Deakin JF (1996) Role of 5-HT in stress, anxiety, and depression. Pharmacol Biochem Behav 54:129-141.

Grahn RE, Will MJ, Hammack SE, Maswood S, McQueen MB, Watkins LR, Maier SF (1999) Activation of serotonin-immunoreactive cells in the dorsal raphe nucleus in rats exposed to an uncontrollable stressor. Brain Res 826:35-43.

Greenwood BN, Kennedy S, Smith TP, Campeau S, Day HEW, Fleshner M (2003) Voluntary freewheel running modulates peripheral catecholamine content and c-Fos expression in the central sympathetic circuit following exposure to uncontrollable stress in rats. Neuroscience, in press.

Imai H, Steindler DA, Kitai ST (1986) The organization of divergent axonal projections from the midbrain raphe nuclei in the rat. J Comp Neurol 243:363-380.

Jacobs BL, Fornal CA (1997) Serotonin and motor activity. Curr Opin Neurobiol 7:820-825.

Kazakov VN, Kravtsov P, Krakhotkina ED, Maisky VA (1993) Sources of cortical, hypothalamic and spinal serotonergic projections: topical organization within the nucleus raphe dorsalis. Neuroscience 56:157-164.

Kendler KS, Karkowski LM, Prescott CA (1999) Causal relationship between stressful life events and the onset of major depression. Am J Psychiatry 156:837-841.

Kent JM, Coplan JD, Gorman JM (1998) Clinical utility of the selective serotonin reuptake inhibitors in the spectrum of anxiety. Biol Psychiatry 44:812-824.

Kirby LG, Allen AR, Lucki I (1995) Regional differences in the effects of forced swimming on extracellular levels of 5-hydroxytryptamine and 5-hydroxyindoleacetic acid. Brain Res 682:189-196.

Kirby LG, Chou-Green JM, Davis K, Lucki I (1997) The effects of different stressors on extracellular 5-hydroxytryptamine and 5-hydroxyindoleacetic acid. Brain Res 760:218-230.

Laaris N, Le Poul E, Hamon M, Lanfumey L (1997) Stress-induced alterations of somatodendritic 5-HT1A autoreceptor sensitivity in the rat dorsal raphe nucleus: in vitro electrophysiological evidence. Fund Clin Pharmacol 11:206-214.

Lanfumey L, Pardon MC, Laaris N, Joubert C, Hanoun N, Hamon M, CohenSalmon C (1999) 5-HT1A autoreceptor desensitization by chronic ultramild stress in mice. NeuroReport 10:3369-3374.
Lowry CA (2002) Functional subsets of serotonergic neurones: implications for control of the hypothalamic-pituitary-adrenal axis. J Neuroendocrinol 14:911-923.

Ma QP, Yin GF, Ai MK, Han JS (1991) Serotonergic projections from the nucleus raphe dorsalis to the amygdala in the rat. Neurosci Lett 134:21-24.

Maier SF (1990) Role of fear in mediating shuttle escape learning deficit produced by inescapable shock. J Exp Psychol Anim Behav Process 16:137-149.

Maier SF, Seligman MEP (1976) Learned helplessness: theory and evidence. J Exp Psychol 105:3-46.

Maier SF, Watkins LR (1998) Stressor controllability, anxiety, and serotonin. Cognit Ther Res 22:595-613.

Maier SF, Silbert LH, Woodmansee WW, Desan PH (1990) Adinazolam both prevents and reverses the long-term reduction of daily activity produced by inescapable shock. Pharmacol Biochem Behav 36:767-773.

Maier SF, Grahn RE, Kalman BA, Sutton LC, Wiertelak EP, Watkins LR (1993) The role of the amygdala and dorsal raphe nucleus in mediating the behavioral consequences of inescapable shock. Behav Neurosci 107:377-388.

Maier SF, Kalman BA, Grahn RE (1994) Chlordiazepoxide microinjected into the region of the dorsal raphe nucleus eliminates the interference with escape responding produced by inescapable shock whether administered before inescapable shock or escape testing. Behav Neurosci 108:121-130.

Maier SF, Grahn RE, Watkins LR (1995a) 8-OH-DPAT microinjected in the region of the dorsal raphe nucleus blocks and reverses the enhancement of fear conditioning and interference with escape produced by exposure to inescapable shock. Behav Neurosci 109:404-412.

Maier SF, Busch CR, Maswood S, Grahn RE, Watkins LR (1995b) The dorsal raphe nucleus is a site of action mediating the behavioral effects of the benzodiazepine receptor inverse agonist DMCM. Behav Neurosci 109:759-766

Martin P, Puech AJ (1996) Antagonism by benzodiazepines of the effects of serotonin-, but not norepinephrine-, uptake blockers in the learned helplessness paradigm in rats. Biol Psychiatry 39:882-890.

Maswood S, Barter JE, Watkins LR, Maier SF (1998) Exposure to inescapable but not escapable shock increases extracellular levels of 5-HT in the dorsal raphe nucleus of the rat. Brain Res 783:115-120.

Maudhuit C, Prevot E, Dangoumau L, Martin P, Hamon M, Adrien J (1997) Antidepressant treatment in helpless rats: effect on the electrophysiological activity of raphe dorsalis serotonergic neurons. Psychopharmacology (Berl) 130:269-275.

Moraska A, Fleshner M (2001) Voluntary physical activity prevents stressinduced behavioral depression and anti-KLH antibody suppression. Am J Physiol Regul Integr Comp Physiol 281:R484-489.

Moraska A, Deak T, Spencer RL, Roth D, Fleshner M (2000) Treadmill running produces both positive and negative physiological adaptations in Sprague-Dawley rats. Am J Physiol Regul Integr Comp Physiol 279: R1321-1329.

Neumaier JF, Petty F, Kramer GL, Szot P, Hamblin MW (1997) Learned helplessness increases 5-hydroxytryptamine1B receptor mRNA levels in the rat dorsal raphe nucleus. Biol Psychiatry 41:668-674.

Neumaier JF, Edwards E, Plotsky PM (2002) 5-HT(1B) mRNA regulation in two animal models of altered stress reactivity. Biol Psychiatry 51:902-908.

Ninan PT (1999) The functional anatomy, neurochemistry, and pharmacology of anxiety. J Clin Psychiatry 60:12-17.

Paxinos G, Watson C (1998) The rat brain in stereotaxic coordinates. New York: Academic.

Petty F, Kramer G, Wilson L, Jordan S (1994) In vivo serotonin release and learned helplessness. Psychiatry Res 52:285-293.

Salmon P (2001) Effects of physical exercise on anxiety, depression, and sensitivity to stress: a unifying theory. Clin Psychol Rev 21:33-61.

Schreiber R, De Vry J (1993) Neuronal circuits involved in the anxiolytic effects of the 5-HT1A receptor agonists 8-OH-DPAT ipsapirone and buspirone in the rat. Eur J Pharmacol 249:341-351.

Seligman ME, Beagley G (1975) Learned helplessness in the rat. J Comp Physiol Psychol 88:534-541.

Sharp JL, Zammit TG, Azar TA, Lawson DM (2002) Stress-like responses to common procedures in male rats housed alone or with other rats. Contemp Top Lab Anim Sci 41:8-14.

Short KR, Patel MR, Lee SH, Tolarino CA (2000) Uncontrollable stress in- 
duced both anxiety and downregulation of dorsal raphe 5-HT1a receptors in rats: both follow the same time course. Soc Neurosc Abstr 26:2267.

Soares J, Holmes PV, Renner KJ, Edwards GL, Bunnell BN, Dishman RK (1999) Brain noradrenergic responses to footshock after chronic activitywheel running. Behav Neurosci 113:558-566.

Solberg LC, Hortaon TH, Turek FW (1999) Circadian rhythms and depression: effects of exercise in an animal model. Am J Physiol 276:R152-R161.

Sprouse JS, Aghajanian GK (1987) Electrophysiological responses of serotoninergic dorsal raphe neurons to 5-HT1A and 5-HT1B agonists. Synapse 1:3-9.

Taylor AH (2000) Physical activity, anxiety, and stress. In: Physical activity and psychological well-being (Biddle SJH, Fox KR, Boutcher CH, eds), pp 10-45. New York: Routledge.

Vertes RP (1991) A PHA-L analysis of ascending projections of the dorsal raphe nucleus in the rat. J Comp Neurol 313:643-668.

Weiss JM, Glazer HI (1975) Effects of acute exposure to stressors on subsequent avoidance-escape behavior. Psychosom Med 37:499-521.

Weiss JM, Goodman PA, Losito BG, Corrigan S, Charry JM, Bailey WH (1981) Behavioral depression produced by an uncontrollable stressor: relationship to norepinephrine, dopamine, and serotonin levels in various regions of the rat brain. Brain Res Rev 3:167-205.

Yehuda R, Antelman SM (1993) Criteria for rationally evaluating animal models of posttraumatic stress disorder. Biol Psychiatry 33:479-486. 